\title{
NMO in pediatric patients \\ Brain involvement and clinical expression
}

\author{
Joaquín A. Peña', María Elena Ravelo², \\ Eduardo Mora-La Cruz ${ }^{3}$, Cecilia Montiel-Nava ${ }^{4}$
}

\begin{abstract}
Objective: To analyze the clinical, neuroimaging characteristics and positivity of the acquaporin water channel (NMO-lgG) in pediatric patients with neuromyelitis optica (NMO). This disorder could have a variable clinical expression. To address such variability, the term NMO spectrum has been suggested. Method: We evaluated six pediatric patients, with a median age of 11 years at the time of the study, with the diagnosis of NMO by the Wingerchuck criteria. Results: All the cases exhibited bilateral optic neuritis (ON). Four patients had abnormalities on brain MRI from the onset,although only three of them developed symptoms correlated to those lesions during the course of their disorder. NMOIgG was positive in $80 \%$. Conclusion: Optic neuropathy is the most impaired feature in NMO patients. Brain MRI lesions are not compatible with multiple sclerosis and positivity of the NMO-lgG are also present in NMO pediatric patients, confirming the heterogeneity in the expression of this disorder.
\end{abstract}

Key words: neuromyelitis optica, multiple sclerosis, optic neuritis, transverse myelitis, pediatric patients.

\section{NMO en pacientes pediátricos: afectación del cerebro y expresión clínica}

\section{RESUMEN}

Objetivo: Analizar las características clínicas y de neuroimagen, y la positividad del canal de agua acuaporin (NMO-lgG) en pacientes pediátricos con neuromielitis óptica (NMO). Este trastorno puede tener una expresión clínica variable. El término espectro de NMO ha sido propuesto para poder incluir la variabilidad. Metodo: Evaluamos seis pacientes pediátricos, con una mediana de edad de 11 años al momento del estudio, con el diagnóstico de NMO de acuerdo a los criterios de Wingerchuck. Resultados: Todos los casos exhibían neuritis óptica bilateral (ON). Cuatro pacientes tuvieron anormalidades en la RM cerebral desde el inicio, aunque solo tres de ellos desarrollaron síntomas relacionados con las lesiones durante el curso de la enfermedad. NMO-lgG fue positiva en el 80\%. Conclusión: Neuropatía óptica es la característica mayormente observada en los pacientes con NMO. Lesiones cerebrales en la RM cerebral no compatibles con esclerosis multiple y positividad de la NMO-IgG están también presentes en los pacientes pediátricos con NMO; lo cual confirma la heterogeneidad en la expresión clínica de este trastorno.

Palabras-claves: neuromielitis óptica, esclerosis múltiple, neuritis óptica, myelitis transversa, pacientes pediátricos.

\section{Correspondence Joaquín A. Peña \\ Urbanización Canaima Calle 42 No. 15-18 Maracaibo-Estado Zulia - Venezuela E-mail: juaco949@hotmail.com juaco949@gmail.com}

Received 12 February 2010

Received in final form 21 September 2010 Accepted 28 September 2010
Neuromyelitis optica (NMO) is an uncommon inflammatory demyelinating disorder characterized by severe acute transverse myelitis (TM) with bilateral simultaneous or sequential optic neuri- tis $(\mathrm{ON})$. Usually reported in adults and rarely in children, NMO has been considered an exceptional manifestation of multiple sclerosis $(\mathrm{MS})^{1-5}$. However, it seems to be a distinct entity with different underly- 
ing pathogenesis, and more severe course $e^{6,7}$. This disorder could have a variable clinical expression which makes difficult its identification during its initial stages. To address such variability the term of neuromyelitis optica spectrum has been suggested ${ }^{6,8}$.

The 1999 diagnostic criteria for NMO required fulfillment of three absolute criteria: optic neuritis, acute myelitis, and no symptoms and/or MRI findings beyond the optic nerves and spinal cord ${ }^{9}$. The Pediatric Multiple Sclerosis Study Group adopted the modified criteria from $2005^{10}$ excluding patients with brain lesions; however, the Study Group acknowledged that these criteria ${ }^{11}$ were also applicable to the pediatric patients ${ }^{8,10}$. In 2006, a new revised diagnostic criteria for definite NMO were defined due to the description of a sensitive and specific serum antibody which was called NMO immunoglobulin $\mathrm{G}$ (NMO-IgG) ${ }^{12,13}$. These criteria included the occurrence of optic neuritis and transverse myelitis and at least two of three supportive criteria: MRI demonstrating involvement of a three or more contiguous spinal cord segments, brain MRI with lesions not compatible with multiple sclerosis or NMO-IgG seropositivity ${ }^{11}$.

The introduction of the new criteria brought some difficulties to the NMO pediatric group (also to the adult group) due to the acceptance of white matter lesions seen in brain MRI ${ }^{11}$.

Although spinal cord lesions are considered the landmark of NMO in children, it has been suggested that around half of the children with the diagnosis of NMO have neuroimaging evidence of brain lesions as well ${ }^{14-16}$. Furthermore, several lesions located in the hypothalamus, brainstem or diffuse cerebral white matter have been described in children with typical features of $\mathrm{NMO}^{14,16}$.

Another controversial diagnostic issue is related to the role of the serologic findings in pediatric NMO concerning the specific serum antibody NMO-IgG. The aquaporin 4-specific (AQP4) water channel autoantibody NMOIgG is detected in $73 \%$ of adults with NMO. However, Banwell, Tenembaun, and cols. ${ }^{16}$ reported that NMO-IgG in pediatric patients is a sensitive marker only for relapsing NMO.

The reports of NMO in children are limited and more complexity is added to the disease characterization. Ten years ago, in 1999, the diagnostic criteria for NMO were first described and ever since two other criteria have been developed. These changes, linked to the low prevalence of the disorder in pediatric ages, have made more difficult the study of the true nature of NMO in children. Due to the dearth of information regarding pediatric NMO we aim to describe the clinical presentation as well as the neuroimaging characterization and the presence of the NMO immunoglobulin $\mathrm{G}$ antibody in a cohort of pediatric patients with NMO.

\section{METHOD}

The patients described in this study were children seen in two different cities in Venezuela: [1] the Neuropediatrics Service of the JM de los Rios Pediatric Hospital, in Caracas, and [2] The University Hospital in Maracaibo. Maracaibo and Caracas are the most populated cities in the country. All patients in Maracaibo were examined by the principal author (Dr. Peña), and those in Caracas by the second author (Dr. Ravelo). The children were first seen between December 2002 and December 2008. The diagnosis of inflammatory demyelination encompassing the spectrum of neuromyelitis optica was based on clinical symptomatology, MRI and serologic analysis, which are in compliance with the most recent pediatric NMO diagnostic criteria ${ }^{11}$, which states that for a NMO diagnosis a child needs: optic neuritis and transverse myelitis and at least two of three supportive criteria (MRI demonstrating involvement of a three or more contiguous spinal cord segments, brain MRI with lesions not compatible with multiple sclerosis or NMO-IgG antibody seropositivity). Patients' information concerning age, symptoms in each bout, number of bouts, laboratory findings, MRI results and treatment were reviewed for each patient.

The brain and spine MRI scans of each patient were reviewed by radiologists who were blind to the diagnosis within the MS spectrum. Most of the scans were performed within two months from the onset of the symptoms and the criteria for the revision were: number, location, size, and enhancement characteristics of the lesions. For the spinal cord scans the spinal segment length was also recorded.

Serum samples from all but one child were analyzed for NMO-IgG antibody in the Mayo Clinic Neuroimmunology Laboratory. For each child, oligoclonal IgG bands in cerebrospinal fluid were tested in the Neuroimmunology Laboratory of the Universidad Central de Venezuela. This study was usually requested after the first MRI scan was performed. Parents and guardians filled out an Informed Consent.

Six patients, five females and one male, were evaluated. Age at symptoms onset ranged from five to 13 years and the median age at the time of the study was 11 years old. They all presented three or more different bouts of a demyelinating disorder with brain and/or vertebral MRI confirmation. Five patients were white / non-Caucasian, and one was Amerindian. All children were of Venezuelan origin, with no family history of any demyelinating disorder.

\section{RESULTS}

Patients' characteristics, clinical, laboratory and MRI findings are exhibited in Table. 
Table. Clinical and demographic characteristics of the sample.

\begin{tabular}{|c|c|c|c|c|c|c|}
\hline Case & 1 & 2 & 3 & 4 & 5 & 6 \\
\hline Age & 12 & 13 & 13 & 12 & 8 & 8 \\
\hline Gender & Female & Female & Female & Male & Female & Female \\
\hline First attack & Vision loss & $\begin{array}{l}\text { Vision loss, } \\
\text { cephalea }\end{array}$ & $\begin{array}{l}\text { Vision loss, } \\
\text { paresthesias, } \\
\text { right arm } \\
\text { weakness }\end{array}$ & $\begin{array}{l}\text { Paresthesia, } \\
\text { paraparesis }\end{array}$ & Vision loss & $\begin{array}{l}\text { Vision loss, } \\
\text { paraparesis, } \\
\text { somnolence, } \\
\text { irritability }\end{array}$ \\
\hline $\begin{array}{l}\text { Interval between } \\
1^{\text {st }} \text { and } 2^{\text {nd }} \text { attacks }\end{array}$ & 7 months & 5 months & 2 months & 6 months & 8 months & 2 months \\
\hline Current treatment & AZT & AZT, Prednisone & Prednisone, AZT & Prednisone & AZT, Prednisone & AZT, Prednisone \\
\hline MRI/spine & $\mathrm{C} 2-\mathrm{C} 5, \mathrm{C} 7-\mathrm{T} 4$ & C6-D8, D10-D11 & C2-C6, D1-D3 & C1-T5 & C6-D8, D10-D11 & C2-C5, D1-D10 \\
\hline Brain & PV & $P V, C R$ & & & $P V, C R, C C$ & $\begin{array}{l}\text { PV, CR, } \\
\text { Cerebellum }\end{array}$ \\
\hline No. of attacks & 5 & 7 & 3 & 3 & 4 & 3 \\
\hline Outcome & $\begin{array}{l}\text { Bilateral vision } \\
\text { loss, paraparesis }\end{array}$ & $\begin{array}{l}\text { Bilateral vision } \\
\text { loss, paraparesis }\end{array}$ & $\begin{array}{l}\text { Bilateral vision } \\
\text { loss, paraparesis }\end{array}$ & $\begin{array}{l}\text { Bilateral vision } \\
\text { loss, paraparesis }\end{array}$ & $\begin{array}{l}\text { Bilateral vision } \\
\text { loss, paraparesis }\end{array}$ & $\begin{array}{l}\text { Bilateral vision } \\
\text { loss, paraparesis }\end{array}$ \\
\hline NMO-lgG (y) & Pos (19) & Pos (15.2) & Pending & $\operatorname{Neg}(13)$ & Pos (12.5) & Pos (11) \\
\hline
\end{tabular}

AZT: azathioprine; PV: periventricular; CR: corona radiate; CC: corpus callosum; ON: optic neuritis.
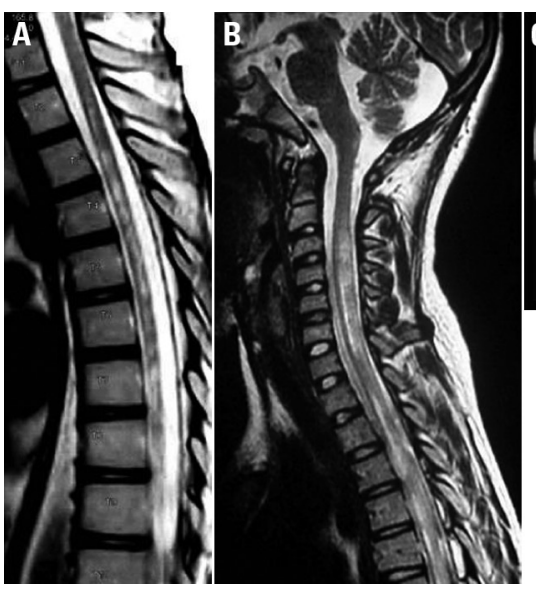

Fig 1. MRI scans of the spinal cord in patients $2[A]$ and $5[B, C]$ with NMO. [A] Longitudinally extensive irregular lesion from T4 to T9 levels. [B] Swollen cervical spinal cord with a longitudinally extensive lesion involving the central area of the cord. [C] Axial imaging of cervical cord showing central pattern of involvement.

\section{Optic neuritis}

In three patients $\mathrm{ON}$ was the initial presentation followed by TM (patients 1, 2 and 5), being apart for seven, five and eight months respectively. On the contrary, ON followed the initial presentation of TM six months later in patient 4, and ON occurred concurrently with TM in patients 3 and 6 . All the cases exhibited bilateral ON with severe impairment in five of them. At the last med-

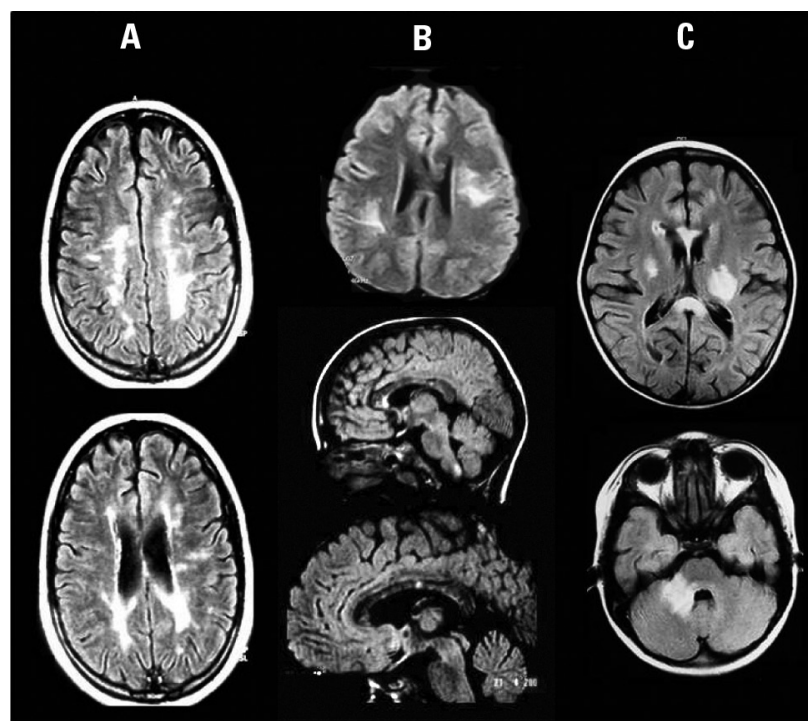

Fig 2. Abnormal brain MRI in patients with NMO. [A] Patient 1: axial T1-weighted images showing several hyperintense lesions in periventricular area. [B] Patient 5: axial T1-weighted images displaying white matter hyperintense lesions; the saggital images show lesions in corpus callosum and pons. [C] Patient 6: axial T1-weighted images of hyperintense lesions in thalamus, corpus callosum, upper pons, and cerebellum.

ical examination, all patients showed evidence of bilateral vision loss and crural paraparesis. Patients 1, 2, 5 and 6 had complete vision loss in both eyes, and the other two children had partial vision recovery in both eyes. 


\section{Transverse myelitis}

As mentioned before, only in one patient the TM was the initial presentation (patient 4); however, clinical symptoms related to TM were seen in all cases during the course of the disease, especially after the second relapse. In addition, the involvement of more than three spinal segments that included cervico-thoracic segments (Fig 1) was present in all children.

\section{Disease course}

All patients presented a relapsing-remitting course, with a median time of six months (range two to eight months) to the second relapset, and an average number of attacks of 4.16 .

\section{Brain involvement}

Although the initial presentation of $\mathrm{ON}$ and the subsequent development of TM was the main form of the disease observed in this sample, another clinical presentations were observed, including crural paraparesis followed by ON or ON appearing concurrently with TM. Four patients exhibited abnormalities on brain MRI from disease onset, but only three developed symptoms related to brain disease during the course of the disorder (patients 2, 5 and 6). Headache, vomiting and vertigo occurred during the third clinical relapse in patient 2 , while aphasia was documented among other findings in patient 5. Patient 6 exhibited seizures, somnolence and irritability as part of her second clinical relapse. Table 1 shows the distribution of the lesions. Although most of the changes were nonspecific, these three patients displayed atypical lesions which included large confluent cerebral or diencephalon lesions, periventricular lesions in the temporal horns of the lateral ventricles, and juxtacortical and central white matter lesions (Fig 2). Patients 5 and 6 had the most striking brain involvement with extensive signal abnormalities in the periventricular white matter and corpus callosum (Fig 2). The MRIs follow up displayed increased brain involvement and progressive brain atrophy in two patients (patient 5 and 6). It is important to mention that none of the images reviewed, or the recorded lesions fulfilled the Barkhof criteria for $\mathrm{MS}^{17}$.

\section{Serology}

NMO-IgG antibody was tested in five patients, with positive results in four of them (80\%). At different stages of the disorder, five patients underwent cerebrospinal fluid (CSF) analysis, two had pleocitosis (35 and 20 cells/ $\mathrm{mm}^{3}$ ), while other two had normal cell count. Oligoclonal bands were negative in all cases, and none of the patients had serologic evidence of other autoimmune antibodies or disorders.

\section{Treatment}

All patients received high-doses of methylprednisolone for the treatment of the acute attacks. One patient was treated with intravenous immunoglobulin for one acute attack (patient 2). Four patients were treated with prednisone and azathioprine simultaneously (patients 2 , 3, 5 and 6).Three of the patients were initially diagnosed as MS, and for that reason they received Interferon bla until the final diagnosis was achieved (patients 1,5 and 6).

\section{DISCUSSION}

As an uncommon entity in pediatric ages, the clinical features of NMO are still being characterized. The demographic features of this sample were similar to those of other cohorts with adults or children, most of the cases were female and all children were from non-white populations, one of them being Amerindian ${ }^{6,8,17,18}$. Recently, race has been considered an important demographic variable for NMO in children, with a predominance of Latin American and African ancestry ${ }^{6}$, and occurring also more frequently in non-white racial groups ${ }^{16,19}$. Race-related findings might indicate that Northern European ancestry is not as determinant in pediatric-onset demyelinating disorders as it is in the adult NMO population ${ }^{8,19}$.

The clinical manifestations in this small sample point toward a diverse initial presentation of NMO in Hispanic children. The optic involvement was bilateral in all patients, leading to bilateral optic atrophy. We consider this an important finding, not only for being the most common presentation of the disease in this sample, but also because of the ON sequelae: $60 \%$ of the children were blind and $40 \%$ had some kind of visual impairment. It seems then, that $\mathrm{ON}$ is the most impairing feature in NMO.

Spinal cord lesions evidenced by spinal MRI had been reported as the single most useful diagnostic feature in the NMO spectrum disorder, both in adults and children $^{7,20}$. For our sample, this additional criterion was observed in the entire group. However, there are patients with NMO who do not have the specific lesion length characteristic of the disorder thus stressing the supportive condition of this criterion.

Four of our cases exhibited the disseminated nature of the central white matter demyelination that extended beyond the optic nerves and spinal cord which is another supportive criteria according to the most recent classification $^{11}$. In fact, recent studies have reported a high frequency of brain MRI abnormalities in patients who fulfill criteria for $\mathrm{NMO}^{14,15,21}$, including nonspecific lesions, atypical and thalamic or hypothalamic lesions that could be related to hypothalamic endocrinopathies, and also extensive cerebral white matter lesions ${ }^{8,22}$. As mentioned before, three patients exhibited signal abnormalities in the diencephalon without apparent metabolic or endocrine findings. 
Symptoms related to brain disorders, which have been reported in other pediatric series, were observed in our sample $^{8-16}$. Throughout the study, one of our patients presented headache, vomiting and vertigo, another had seizures while other had symptoms of expressive aphasia in the course of the disorder, probably related to an extensive tumefactive white matter lesion in the left hemisphere. Moreover, in four patients there were an atypical brain MRI since the initial relapse with extensive brain damage on follow-up. Such evolution pattern has been well described in NMO literature and should prompt neuropediatricians to follow-up their NMO patients, with brain MRI, regardless of the initial presentation.

Inclusion of the autoantibody testing in the recently revised diagnostic criteria for NMO led to the distinction of this disorder from MS and other autoimmune CNS diseases. This antibody, which has $73 \%$ sensitivity and $91 \%$ specificity, has classified NMO as a brain blood barrier channelopathy with abnormal humoral immunity activation $^{12}$. It was positive in $80 \%$ of the patients in our sample. However, 10 to $25 \%$ of the patients clinically diagnosed as $\mathrm{NMO}$ are seronegative for NMO-IgG. An important finding for our sample was that all the patients who had positive NMO-IgG were the same who showed brain lesions at the MRI. Published studies report that sites of high brain aquaporin 4 expressions seem to correspond with brain MRI abnormalities in this group of patients ${ }^{13,23}$.

According to our findings, we can conclude that demographic characterization of $\mathrm{NMO}$ in children is similar to adults', exhibiting a higher prevalence of females and non-white populations. The characterization of this entity in children could be done by using the new 2006 criteria, with an emphasis on the possibility of brain lesions or symptoms of brain involvement that do not meet MS criteria. The presence of $\mathrm{ON}$ and TM as required criteria, in addition to the three supportive criteria in pediatric samples, was also evident in this study.

This study highlights the association of seropositivity of NMO-IgG and the presence of brain lesions in the NMO pediatric group. The heterogeneity of symptoms and neuroimaging characterization suggest that the term "neuromyelitis optica" should be applied to a broader clinical syndrome in pediatric patients.

\section{REFERENCES}

1. Galetta SL, Bennett J. Neuromyelitis optica is a variant of multiple sclerosis. Arch Neurol 2007;64:901-903.

2. Frohman EM, Kerr D. Is neuromyelitis optica distinct from multiple sclerosis? something for "lumpers" and "splitters." Arch Neurol 2007;64:903-905.

3. Roach ES. Is neuromyelitis optica a distinct entity? Arch Neurol 2007;64:906.

4. Weinshenker BG. Neuromyelitis optica is distinct from multiple sclerosis. Arch Neurol 2007:64:899-901.

5. Lana-Peixoto MA. Devic's neuromyelitis optica: a critical review. Arq Neuropsiquiatr 2008;66:120-138.

6. Wingerchuk DM, Lennon VA, Lucchinetti CF, Pittock SJ, Weinshenker BG, The spectrum of neuromyelitis optica. Lancet Neurol 2007;6:805-815.

7. Pittock SJ. Neuromyelitis optica: a new perspective. Semin Neurol 2008;28: 95-104

8. Lotze TE, Northrop JL, Hutton GJ, Ross B, Schiffman JS. Spectrum of pediatric neuromyelitis optica. Pediatrics 2008;122:1039-1047.

9. Wingerchuk DM, Hogancamp WF, O'Brien PC, Weinshenker BG. The clinical course of neuromyelitis optica (Devic's syndrome). Neurology 1999;53: 1107-1114

10. Krupp LB, Banwell B, Tenembaum S. Consensus definitions proposed for for pediatric multiple sclerosis and related disorders. Neurology 2007;68 (Suppl 2):S7-S12.

11. Wingerchuk DM, Lennon VA, Pittock SJ, Lucchinetti CF, Weinshenker DM. Revised diagnostic criteria for neuromyelitis optica. Neurology 2006;66: 1485-1489.

12. Lennon VA, Wingerchuk DM, Kryzer TJ, et al. A serum autoantibody marker of neuromyelitis optica: distinction from multiple sclerosis. Lancet 2004; 364:2106-2112.

13. Lennon VA, Kryzer TJ, Pittock SJ, Verkman AS, Hinson SR. IgG marker of optico-spinal multiple sclerosis binds to the aquaporine-4 water channel. J Exp Med 2005;202:473-477.

14. Pittock SJ, Lennon VA, Krecke $K$, et al. Brain abnormalities in neuromyelitis optica. Arch Neurol 2006;63:390-396.

15. Poppe AY, Lapierre Y, Melancon D, et al. Neuromyelitis óptica with hypothalamic involvement. Mult Scler 2005;11:617-621.

16. Banwell B, Tenembaum S, Lennon VA, et al. Neuromyelitis optica-IgG in childhood inflammatory demyelinating CNS disorders. Neurology 2008;70: 344-352.

17. Peña J, Montiel-Nava C, Ravelo ME, Gonzalez S, Mora La Cruz E. Multiple sclerosis in children: clarifying its place among the demyelinating spectrum. Invest Clin 2006;47:413-425.

18. Ghezzi A, Bergamaschi R, Martinelli V, et al. Clinical characteristics, course and prognosis of relapsing Devic's neuromyelitis optica. J Neurol 2004;251:47-52.

19. Ness JM, Chabas D, Sadovnick AD, et al. Clinical features of children and adolescents with multiple sclerosis. Neurology 2007;68(Suppl 2):S37-S45.

20. Papais-Alvarenga RM, Miranda Santos CM, Puccioni-Sohler M, et al. Optic neuromyelitis síndrome in Brazilian patients. J Neurol Neurosurg Psychiatr 2002;73:429-435

21. Misu T, Fujihara K, Nakashima I, Sato S, Itoyama Y. Intractable hiccup and nausea with periaqueductal lesions in neuromyelitis optica. Neurology 2005; 65:1479-1482

22. Nakamura M, Endo M, Murakami K, et al. An autopsied case of neuromyelitis optic with a large cavitary cerebral lesion. Mult Scler 2005;11:735-738.

23. Lucchinetti CF, Mandler RN, McGavern Det al. A role for humoral mechanisms in the pathogenesis of Devic's neuromyelitis optica. Brain 2002;125: 1450-1461. 